
\title{
25 Research Soure \\ Determination of the Environmental Flow Using the Modern Optimization Methods for Release Flow based on Game Theory
}

\section{Amir Foroughian}

Islamic Azad University

Ehsan Derikvand ( $\sim$ gonasharkan@gmail.com )

Islamic Azad University

Hossein Eslami

Islamic Azad University

Saeb Khoshnavaz

Islamic Azad University

\section{Research Article}

Keywords: Water flow optimization, Qual-2K model, Game theory (Nash function), Environmental flow

Posted Date: October 20th, 2021

DOI: https://doi.org/10.21203/rs.3.rs-887234/v1

License: (1) This work is licensed under a Creative Commons Attribution 4.0 International License. Read Full License 


\section{Abstract}

To prevent environmental risks and preserve water quality, it is necessary to determine the environmental flow of rivers. Water release from reservoirs can be used to determine the environmental flow and water quality at the downstream of a dam. In this study, considering the quantitative and qualitative objectives, water release from Dez dam was suggested as a way for preserving the environment of river. To identify the optimal release flow of Dam, an environmental zone was determined using the hydrological methods of Tennant and aquatic base flow. The Qual-2k model was used to simulate 6 quality parameters in River. The results proved its good potential for simulation of the studied quality parameters including BOD. The optimal river flow was determined by Game theory, and different qualitative and quantitative scenarios were studied using the Nash multiplying function. The results showed, with increases in qualitative and quantitative objectives of the problem, the optimal release flows are decreased and increased, respectively.

\section{Introduction}

Water has always been among the most important needs of human, animal and plants, and rivers have played an important role in formation of civilizations through the history. Today, more water is required due to rapid growth of population and increase of water demands. Therefore, it is inevitable to construct reservoirs for providing the required water. Moreover, considering the conflict between river discharge regime and water demands for drinking, industry and agriculture, construction of storage systems is one of the best procedures for using water resources, adjusting the flows of rivers and providing the water requirement (Bouaroudj et al., 2019). Water scarcity and the need for proper water use management and preventing loss of water make it necessary to perform dam construction projects. Dams, by storing and regulating the water, have become an essential tool for development and conservation of rivers. They have considerable advantages such as social and economic development, flood control and road traffic control. However, from negative point of view, dams can pose many environmental problems such as water pollution and degradation of river environment. The qualitative and quantitative studies on environment of the

dam-controlled rivers are useful for mitigation of water-related disasters.

Therefore, paying attention to environmental flow should be given priority in water resource management (Chen et al., 2020).

Complexities of water resource optimization problems stem from the variety of decision-making criteria and objective functions. Some of these problems cannot be solved by classic optimization procedures or require a large amount of time and cost. Thus, it would be essential to apply modern tools and methods for solving such problems (Pourghasemi., 2020). In complicated issues related to optimization of dam reservoir operation, the possibility of solving the problems by traditional optimization methods and explicit computational methods would be decreased with the increase of dimensions, variables and constraints, and finding a definite response would be very difficult (Ahmad et al., 2014). Therefore, application of powerful optimization methods for optimizing one-reservoir or multi-reservoir systems has become highly important. In recent years, optimization procedures in hydrological and environmental studies have attracted many researchers' attention.

Farhadian et al., (2020) attempted to develop a general method for determining reservoir discharge which supports river ecosystem and is qualitative, quantitative and environmental at the same time. For this purpose, 
first they determined the required environmental flow and then detected the contamination sources of Karun River at the downstream of Gotvand reservoir. They also investigated water quality of the river, applied its BOD concentration to the release zone of reservoir and carried out the simulations using the Qual-2k model. Finally, they determined the qualitative and quantitative objectives and defined three scenarios for weights of the objectives. The results showed that reduction of release rate from the reservoir increases the hazards to the river environment.

Suwal et al., (2020) studied the optimization of a cascade reservoir performance focusing on environmental flows of different classes in environmental management. They calculated the environmental flows of each class of environmental management using "global environmental flow calculator software" and solved the model by NSGA-II. Results showed that NSGA-II was effective in finding the optimal solutions but could not be used exclusively for an exhaustive decision making. They also suggested that a given amount of water discharge from a dam could reduce the adverse effects of reservoirs and dams on river ecosystem.

Dehghanipour et al., (2020) used an optimizing simulation (simultaneous use of simulation models of surface water (WEAP) and groundwater (MODFLOW) dynamically) to study Urumieh lake watershed. They found that product yields were significantly decreased in case of drought. However, this decrease could be prevented by increasing the capacity of groundwater pumping and temporary reduction of minimum flow demands of the lake.

Zhang et al., (2015) using Qual-2K model, investigated the reasons behind deterioration of water quality in Taihu Lake, China. They determined the maximum permissible emission level for four pollution indices (i.e. total nitrogen, total phosphorous, ammonia and COD).

Cai et al., (2013) applied four scenarios of zero environmental flow, minimum environmental flow, appropriate environmental flow and designed environmental flow for evaluating the potential hydrological changes using range of variability approach (RVA). Amounts of electricity power generation and hydrological changes indicated that sufficient energy generation and the lowest hydrological changes could be obtained under the fourth scenario.

The temporal and spatial concentrations of a pollutant entered a lake can be affected by three factors :

1) Transport which is defined as carrying the pollutant with water flow to the downstream of a river and depends on flow velocity.

2) Diffusion which accounts for pollution distribution in water and converts point-source pollution to diffuse pollution.

3) Attenuation which is defined as pollution elimination and decreasing the amount of pollutants with time.

Two important factors can affect the environmental damage after a pollutant enters a river: 1) the pollution concentration in the contaminated zone of the river, and 2) the distance for pollution to settle in a permissible range through diffusion and attenuation processes. Having constant effects on pollution physics and riverbed, the above-mentioned parameters can influence the river flow rate. Thus, it is crucial to determine the appropriate river flow that can supply the environmental water requirement and minimize the damage posed by pollution. 
The main objective of this study is to decrease the pollution concentration and the time needed for concentration reduction by combining hydrological procedures and Game Theory.

\section{Materials And Methods 2.1. Study area}

Dez Dam is a tall, double-curvature concrete dam which is used for hydroelectric power generation. It has been founded on a gorge in a conglomerate formation deeply eroded by water flow of Dez River. The dam site is located about $23 \mathrm{~km}$ far from the northern part of Dezful and $22 \mathrm{~km}$ away from Andimeshk in Khuzestan province. The dam, with an area of about $50 \mathrm{~km}^{2}$, has a total capacity of $3.3 \times 10^{9} \mathrm{~m}^{3}$. Its height over foundation is $203.5 \mathrm{~m}$ and its crest length is $212 \mathrm{~m}$. It supplies the irrigation water for 125,000 ha of the downstream lands and plays a vital role in controlling the floods at the upstream of the reservoir. The installed capacity of its power plant is 520 MW. Dez River basin is a 3rd -grade basin and subset of Big Karun basin which is subset of Persian Gulf basin. Precipitations in the western and northwestern foothills of Zagros mountain mainly occur in the form of snow in autumn and winter. Melting of this snow provides a large amount of annual surface runoff in this basin (Saghi et al., 2015). Figure 1 shows the geographical location of Dez Dam.

Location and distance of pollution from Dez river.

\subsection{Methods}

To determine the optimum release flow, initially, the upper and lower bounds of the environmental flow were identified using the hydrological method of Tennant and aquatic base-flow. Then, movement of pollution in the river was simulated using Qual-2K software, and the obtained results were used to find the optimal flow through conflict resolution in Game theory (Nash function) and to apply the relative weights to the objectives. The data related to river flow from the dam to the intersection of Dez and Karun rivers at Bandghir point were used to determine the environmental flow. These data included the release flow from Dez dam, hydrological characteristics of river, location of pollution sources, flow rate, pollution concentration, diffusion coefficients and attenuation coefficients. Among the hydrological procedures, Tennant and aquatic base-flow methods were the most common methods which had a good fit with the conditions of the study area. Therefore, these two methods were employed for computing the environmental flow in Dez River.

\subsection{Determination of the environmental flow using the hydrological method of Tennant}

Tennant studied several rivers in some states of the USA to evaluate the environmental flow. He finally presented the Tennant method based on the rendered studies. In this method, which is inexpensive and easy to use, first, the natural and normal flows of a river are obtained from the historical data and the mean annual flow is calculated, and next, $10 \%, 30 \%$ and $60 \%$ of the river natural flows are recommended as environmental flow (10\%: minimum, $30 \%$ : partly suitable, and $60 \%$ : suitable for animals and aquatics). Compared to the relatively complicated methods, the Tennant method is a simple, applicable and standard method that can be used when little data are available. This technique relies on only the mean annual flow of river (Mishra et al., 2019).

\subsection{Qual-2k model}


Qual-2k is the latest type of Qual series models which can analyze uncertainty. This model is capable of solving the river-related equations in both static and pseudo-dynamic conditions. In the present study, this model was used for simulation of the quantitative variables along the river in a dynamic condition, and the river flow rates for point and non-point pollutants were considered constant. This model can simulate the parameters such as dissolved oxygen (DO), biochemical oxygen demand (BOD), temperature, acidity, suspended matter, total phosphorous, organic phosphorous, total nitrogen, ammonia-nitrogen, nitrate-nitrogen, nitrite-nitrogen, organic nitrogen and algal nitrogen in river network. Furthermore, it can consider longitudinal diffusion, sediment oxygen demand, carbonaceous matter precipitation, nitrification and denitrification in the simulation of water quality parameters (Wang et al., 2013).

\subsection{Game theory}

Game theory is a mathematical method for analyzing the problems associated with conflict situations. It includes the decisions that each player should make or choose from various choices based on game rules to increase his/her winning chance. Game theory presents a model for comparing different strategies and predicting the game result. This theory examines the conflicts existing in a game and the players' reactions to these conflicts. Having a perfect understanding of the Game theory, conflicts and reactions can be correctly investigated and players can be directed to the correct decisions. Game theory was initially applied for understanding a series of economic behavior, but today it is used in different fields including economics, social, environmental, computer, political, psychological and philosophical sciences (Parrachino et al., 2006).

\subsection{Conflict resolution theory of Nash}

In decision-making process, the decision-making becomes difficult and causes conflicts if more than one decision-maker exists. Nash's theory (1954) is one of the conflict resolution methods. Nash presented a series of conditions which should be fulfilled. The conditions of Nash's theory are: 1) the decision-makers cannot allocate excessive sources other than the available ones, 2) none of the decision-makers enter an agreement in which the utility function is less than the minimum utility level, and 3) no better answer/strategy is available for the decision-makers(Nafarzadegan et al., 2018). Nash theory of conflict resolution has been presented for resolving the conflicts between two individuals. Harsanyi and Selten (1988) developed this theory in the form of an optimized model for resolving the conflicts between more than two individuals. Since multiple results are obtained for each person in this model, it is called multiplying model of Nash.

\section{Results And Discussion}

\subsection{Hydrological method of Tennant}

Tennant method is one of the most useful methods for determining the environmental flow of rivers. To use the Tennant method, the mean annual natural flow rate of Dez River $\left(144.70 \mathrm{~m}^{3} . \mathrm{s}^{-1}\right)$ was obtained from the Water and Electricity Organization in Khuzestan (Table 1). Tennant suggests the mean river flow of $10 \%-60 \%$ for the environmental flow. According to the values presented in Table 1, the environmental flow rates in Dez River fall within 14.47 and $86.82 \mathrm{~m}^{3} \cdot \mathrm{s}^{-1}$. Therefore, the environmental life would face a sever crisis in flow rates lower than the minimum environmental flow rate $\left(14.47 \mathrm{~m}^{3} \cdot \mathrm{s}^{-1}\right)$. Similarly, the environmental life would face some hazards, such as inappropriate condition for aquatic breeding, in flow rates higher than the maximum environmental flow rate $\left(86.82 \mathrm{~m}^{3} \cdot \mathrm{s}^{-1}\right)$. Tennant method is the most prominent method used in the hydrological procedure of 
evaluating the environmental flow in rivers (Mazvimavi et al., 2007). Since the Tennant method has been mainly used to study the large permanent rivers, its application in the rivers with high monthly fluctuations may lead to some problems. For example, by ignoring the monthly and seasonal fluctuations of river flow rate, it can lead to miscalculation of the mean monthly yield in determining the environmental demand of a river. This is due to the fact that, in this method, the environmental demand is defined as a part of the mean annual demand(Theodoropoulos et al., 2018). Karimi et al., (2017)

calculated the mean annual natural flow rate of a river as $80.18 \mathrm{~m}^{3} . \mathrm{s}^{-1}$ using the Tennant method. They reported the flow rates of $8.02 \mathrm{~m}^{3} . \mathrm{s}^{-1}$ and $24.06 \mathrm{~m}^{3} . \mathrm{s}^{-1}$ during October-March and April-September respectively. Watt et al., (2007) studied the rivers in Ontario, Canada and concluded that the Tennant and Tessman methods did not suit the conditions. They believed that only the modified types of these methods could be used in Ontario.

Table 1. Mean annual flow rates of Dez River during the statistical period of $2009-2016\left(\mathrm{~m}^{3} . \mathrm{s}^{-1}\right)$

\begin{tabular}{llllllllll} 
& 2009 & 2010 & 2011 & 2012 & 2013 & 2014 & 2015 & 2016 & Average \\
\hline $\begin{array}{l}\text { Annual } \\
\text { average }\end{array}$ & 189.11 & 91.299 & 148.21 & 162.42 & 123.83 & 142.43 & 140.15 & 160.17 & 144.70 \\
\hline Tennant (10\%) & 18.911 & 9.1299 & 14.821 & 16.242 & 12.383 & 14.243 & 14.015 & 16.017 & 14.470 \\
\hline Tennant (60\%) & 113.47 & 54.779 & 88.926 & 97.452 & 74.298 & 85.458 & 84.90 & 96.101 & 86.82
\end{tabular}

\subsection{Hydrological method of aquatic base-flow}

This method it based on the hypothesis that the mean flow rate in the driest month of the year is enough for aquatic life, unless extra flow rate is necessary for reproduction (Theodoropoulos et al, 2018). In this method, the environmental flow is equal to the minimum mean monthly rate of natural river flow. Therefore, the mean monthly flow was calculated using the inflow data of Dez River (Table 2). The minimum mean monthly flow of $40.893 \mathrm{~m}^{3} . \mathrm{s}^{-1}$ was considered as the environmental base-flow of aquatics (This value falls within $14.47 \mathrm{~m}^{3} . \mathrm{s}^{-1}$ and $86.82 \mathrm{~m}^{3} . \mathrm{s}^{-1}$ which have been suggested by Tennant as $10 \%$ and $60 \%$, respectively). Thus, to apply the Tennant and aquatic base-flow methods and to reach a higher reliability, the environmental flow rate was considered to be in the range of 10 and $110 \mathrm{~m}^{3} \cdot \mathrm{s}^{-1}$.

Table 2. A Summary of the statistics used for determination of the environmental flow using aquatic the baseflow method 


\begin{tabular}{|c|c|c|c|c|c|c|c|c|c|}
\hline & $\begin{array}{l}2008- \\
2009\end{array}$ & $\begin{array}{l}2009- \\
2010\end{array}$ & $\begin{array}{l}2010- \\
2011\end{array}$ & $\begin{array}{l}2011- \\
2012\end{array}$ & $\begin{array}{l}2012- \\
2013\end{array}$ & $\begin{array}{l}2013- \\
2014\end{array}$ & $\begin{array}{l}2014- \\
2015\end{array}$ & $\begin{array}{l}2015- \\
2016\end{array}$ & mean \\
\hline March - April & & 204.86 & 164.44 & 311.18 & 301.77 & 222.86 & 231.66 & 453.12 & 269.98 \\
\hline April- May & & 145.19 & 188.58 & 456.22 & 294.61 & 201.03 & 205.84 & 298.42 & 255.7 \\
\hline May- June & & 97.544 & 112.57 & 186.68 & 155.93 & 109.78 & 131.75 & 148.35 & 134.66 \\
\hline June- July & & 62.998 & 65.171 & 108.54 & 88.358 & 65.425 & 81.637 & 93.549 & 80.811 \\
\hline July- August & & 46.495 & 44.314 & 70.237 & 50.768 & 43.867 & 53.111 & 60.961 & 52.822 \\
\hline $\begin{array}{l}\text { August- } \\
\text { September }\end{array}$ & & 40.127 & 48.323 & 52.938 & 42.52 & 34.216 & 41.384 & 49.049 & 44.08 \\
\hline $\begin{array}{l}\text { September- } \\
\text { October }\end{array}$ & & 35.765 & 38.608 & 47.828 & 37.238 & 32.571 & 38.849 & 55.395 & 40.893 \\
\hline $\begin{array}{l}\text { October- } \\
\text { December }\end{array}$ & & 82.11 & 161.42 & 51.047 & 88.127 & 61.236 & 50.853 & 117.76 & 87.508 \\
\hline $\begin{array}{l}\text { December- } \\
\text { November }\end{array}$ & 258.64 & 99.269 & 217.05 & 70.451 & 89.284 & 156.98 & 199.58 & 258.64 & 168.74 \\
\hline $\begin{array}{l}\text { November- } \\
\text { January }\end{array}$ & 118.56 & 64.354 & 156.94 & 87.313 & 60.739 & 255.89 & 146.91 & 118.56 & 126.16 \\
\hline $\begin{array}{l}\text { January- } \\
\text { February }\end{array}$ & 159.32 & 127.52 & 285.55 & 157.25 & 134.74 & 296.81 & 175.58 & 159.32 & 187.01 \\
\hline $\begin{array}{l}\text { February- } \\
\text { March }\end{array}$ & 223.4 & 119.56 & 309.78 & 348.5 & 135.92 & 234.4 & 334.35 & 223.4 & 241.16 \\
\hline
\end{tabular}

\subsection{Study of the river water quality}

Investigation of water quality at the time of simulation can provide a good perspective about the intended river and further studies. For this purpose, the parameters for August were used to study the quality of water and perform the simulation (Water and Electricity Utilities, 2016) (Table 3).

Table 3. Quality of water in monitoring stations and comparisons with the related standards 
Dissolved oxygen is an important parameter for the water bodies. Yustiani et al., (2019) in their study, reported that DO concentrations were in the range of 3.20 and $3.68 \mathrm{mg} \cdot \mathrm{L}^{-1}$. BOD increases of about $6 \%$ and $25 \%$ were observed at $36.5 \mathrm{~km}$ away from the first zone and from there to the fresh water zone, respectively. This could be due to the presence of point pollutants in the first zone. Moreover, BOD showed $40 \%$ increase in the second zone and decreased with a slow slope of $1.5 \%$ in the third zone. Chemical oxygen demand (COD) showed $9.4 \%, 17 \%$ and $5.23 \%$ increases in the first, second and third zones, respectively. Zhang et al., (2015) evaluated the reasons for water quality reduction in Taihu River, China using the Qual-2k model. They determined the maximum permissible pollutant discharge for four pollution indices (i.e. total nitrogen, total phosphorous, ammonia, and COD). $\mathrm{N}-\mathrm{NH}_{4}$ exhibited 35\%, 40\% and 10\% increases in the first, second and third zones. The changing trend of $\mathrm{N}$ $\mathrm{NO}_{3}$ concentration in 2016 showed a constant growth with a slow slope of $1.5 \%$ along Dez River and increase of $46 \%$ from top to bottom of Dez Dam. In 2016, phosphorous ( $\mathrm{P}-\mathrm{PO}_{4}$ ) experienced $24.3 \%$ and $24.4 \%$ increase in the first and second zones and $20 \%$ decrease in the third zone.

\subsection{Evaluation of the model}

After model calibration, it was evaluated to check the simulation accuracy and the reliability of results. For this purpose, it was attempted to minimize the difference between the observed values and simulated parameters using root mean square error (RMSE), correlation coefficient $\left(R^{2}\right)$ and mean standard error (MSE). It was found that more optimal models could be obtained in higher RMSE and MSE and lower $\mathrm{R}^{2}$ values. Table 4 indicates the results of evaluating the simulation model and comparison of the observed and simulated values. Yustiani et al., (2019) claimed that analyzing the quality data of river through modeling and simulation is a useful tool for water pollution control in rivers, and modeling is more cost- and time-effective than direct measurement.

Table 4. Results of calibration and verification of Qual-2k model

\begin{tabular}{|c|c|c|c|c|c|c|c|}
\hline \multicolumn{2}{|c|}{ period } & parameters & 2013Calibration & \multicolumn{4}{|c|}{ 2016Verification } \\
\hline & & (ppm)RMSE & $\left.\mathrm{ppm}^{2}\right)(\mathrm{MSE}$ & $\mathbf{R}^{2}$ & (ppm)RMSE & $\left.\mathrm{ppm}^{2}\right)(\mathrm{MSE}$ & $\mathrm{R}^{2}$ \\
\hline \multirow[t]{6}{*}{ Dez river } & DO & 0.68 & 0.065 & 0.92 & 0.89 & 0.072 & 0.91 \\
\hline & BOD & 0.42 & 0.067 & 0.93 & 0.41 & 0.75 & 0.91 \\
\hline & COD & 1.89 & 0.28 & 0.87 & 1.78 & 0.033 & 0.90 \\
\hline & $\mathrm{N}-\mathrm{NH} 4$ & 0.087 & 0.028 & 0.89 & 0.097 & 0.039 & 0.86 \\
\hline & N-NO3 & 0.89 & 0.074 & 0.91 & 0.985 & 0.065 & 0.92 \\
\hline & P-P04 & 0.037 & 0.061 & 0.90 & 0.047 & 0.079 & 0.88 \\
\hline
\end{tabular}

\subsection{BOD simulation based on maximum and minimum flow rates of river}

BOD quality parameter was used for simulation (Table 5). This parameter was selected because it shows deterioration properties and is more appropriate for illustrating the level of quality in a river. Simulation was performed in the environmental area mentioned in previous sections with one unit distance from the release flow (the river flow rate was considered as $10-110 \mathrm{~m}^{3} \cdot \mathrm{s}^{-1}$ ). Figure 3 indicates the BOD changes for maximum and 
minimum environmental flows $\left(10-110 \mathrm{~m}^{3} \cdot \mathrm{s}^{-1}\right)$, and Table 5 presents the BOD simulation results. To perform the simulation by Qual-2k model, the time required for each simulation was estimate. It should be noted that simulation time is the time needed for the river pollution concentration to become balanced. The minimum time required to reach equilibrium is equal to the time needed for pollution to move from the beginning to the end of simulation path. This time could be calculated in the Qual-2k model using the flow velocity and Manning equation. The time for simulating Dez River was calculated as 1 day. Farhadian et al., (2020) declared that changes in BOD index have the largest effect on the environment, especially the living organisms in aquatic environments.

Table 5. Summary of simulation results for BOD parameter at minimum and maximum levels

\begin{tabular}{|c|c|c|c|c|c|c|c|c|c|c|c|c|}
\hline \multirow[b]{2}{*}{ Distance(km) } & \multicolumn{12}{|c|}{ Dez river } \\
\hline & 20 & 25 & 40 & 60 & 62 & 80 & 100 & 120 & 140 & 160 & 180 & 185 \\
\hline (max flow)Bod & 1.5 & 1.5 & 2 & 2.3 & 3.4 & 3.2 & 3.11 & 3 & 2.5 & 2.2 & 1.8 & 1.5 \\
\hline (min flow)Bod & 10.2 & 10.4 & 8 & 8.5 & 10 & 7 & 6 & 5 & 4 & 3.5 & 3 & 2.5 \\
\hline
\end{tabular}

\subsection{Calculation of mean concentration and contact length as the dam objectives}

After the simulation process, the BOD diagram was obtained for different flow rates released from Dez Dam (Fig 4). Using this diagram, the mean concentration of BOD pollution and contact length could be obtained at different distances. It should be noted that reduction of DO content in surface sources is due to the biological activities of bacteria and living organisms during the decomposition of BOD and nitrogen and their conversion to inorganic materials such as $\mathrm{CO}_{2}$ and nitrate. Normally, this process is regarded as an index in study of water sources quality. This index describes how multiple parameters of water quality (including BOD, nitrogen and phosphorous materials which are used as pollution indices) can affect the lives of aquatic organisms, flow rate and velocity as self-purification (self-cleaning) indices (Wei et al., 2009). To calculate the mean concentration, concentrations over $1 \mathrm{mg} . \mathrm{L}^{-1}$ were included in averaging and the obtained value was considered as the mean BOD concentration per release flow. Since the water with BOD concentrations of lower than $1 \mathrm{mg} \cdot \mathrm{L}^{-1}$ is known as pure water, 1 mg.L $\mathrm{L}^{-1}$ was selected as the permissible limit for BOD (Farhadian et al., 2020). Finally, the mean BOD concentration was obtained according to Eqs. 1 and 2.

$$
\begin{aligned}
& C_{o, i}= \begin{cases}C_{i}-1 & \text { if } C_{i} \geq 1 \\
0 & C_{i}<1\end{cases} \\
& C_{\text {mean }}=\frac{\sum_{i=1}^{n t} c_{i}^{\prime}}{n t}
\end{aligned}
$$

Where, $C_{0, i}$ is $B O D$ concentration at i point which is higher than $1 \mathrm{mg} / \mathrm{L} ; i$ is the number of pollution concentration measurements; $C$ is BOD concentration at ith $\left(\mathrm{mg}^{\mathrm{L}} \mathrm{L}^{-1}\right) ; \mathrm{C}_{\text {mean }}$ is the mean concentrations higher than $1 \mathrm{mg} \cdot \mathrm{L}^{-}$ 1 and $\mathrm{nt}$ is the total number of pollution concentration measurements. Contact length was calculated as the necessary distance for decreasing the pollution concentration to the permissible level ( $\left.1 \mathrm{mg} . \mathrm{L}^{-1}\right)$. Mean concentration and contact length were calculated and the diagram was drawn for the given flow rates (Fig 4). As can be seen in Fig. 4, due to the increase of water volume, the concentrations of river pollutants decrease with 
the increase of release flow and vice versa. In addition, with the increase of release flow, unpermitted concentrations move farther along the river and thereby the contact length increases as a result of faster water flow. For example, with a flow rate of $50 \mathrm{~m}^{3} \cdot \mathrm{s}^{-1}, 155 \mathrm{~km}$ is necessary for BOD dissolving and reaching the standard level. This would be important in determining the operational site of the river and crucial for the downstream areas which rely on dam for drinking water. In the study area, which covers many cities and villages, the release flow should be adjusted to reduce the pollution concentration to permissible levels before reaching the operational site. Considering the deterioration of BOD in Dez River, its concentration was reduced after a given distance $(144 \mathrm{~km})$ and reached the permissible level. Yustiani et al., (2019) suggested the range of 8.06$23.83 \mathrm{mg} . \mathrm{L}^{-1} 1$ as the maximum concentration for BOD. Farhadian et al., (2020) used the Qual-2k model to determine the BOD concentration in a river and estimated the minimum and maximum daily diffusions of BOD as $13.7 \mathrm{~m}^{3} \cdot \mathrm{s}^{-1}$ and $458 \mathrm{~m}^{3} \cdot \mathrm{s}^{-1}$ respectively. Table 6 presents the mean change of concentration and contact length in different flows.

Table 6. Summary of the mean change of concentration and contact length in different flows

\begin{tabular}{|llllllllllll|}
\hline \multicolumn{2}{|c|}{ Dez river } & & & & & & & & & & \\
\hline \\
$\left(\mathrm{m}^{3} . \mathrm{s}^{-1}\right)$ Discharge & 10 & 20 & 30 & 40 & 50 & 60 & 70 & 80 & 90 & 100 & 110 \\
\hline $\mathrm{mg} / \mathrm{IC}($ Mean) & 6 & 4 & 3.5 & 3 & 2.8 & 2.6 & 2.4 & 2.2 & 2 & 1.8 & 1.8 \\
\hline $\mathrm{L}(\mathrm{km})$ & 146 & 146.2 & 148 & 150 & 155 & 158 & 158.7 & 159.4 & 160.1 & 160 & 162 \\
\hline & & & & & & & & & & & \\
\hline
\end{tabular}

\subsection{Optimal release flow}

Considering the social problems, high costs and expansion of areas, the pollutants entering the rivers cannot be reduced or removed. Therefore, control of release flow from dams seems to be the best way for mitigation of pollution. Higher flows released to river increase the contact length and decrease the mean concentration of pollutants. Knowing that reduction of pollution concentration is related to contact length, the release flow should be adjusted to optimize the mean concentration and contact length. Figure 5 shows the mean concentration and contact time related to the release flow from Dez River. Since the cities such as Mollasani, Ahwaz, Abadan and Khorramshahr at the downstream of Dez River rely on this river for drinking water, maintaining the good quality of drinking water seems to be essential for determining the release flow. Therefore, the objectives such as hydropower electricity generation, flood control, water adjustment for the downstream agricultural lands and reservoir reliability should be taken into account in optimization of the release flow from dams. Dahmani et al., (2018) demonstrated that the suitable water release could only be defined by combining the liquid flows and the storage state in reservoir.

\subsection{Using Nash function}

There might be conflict of interests among the mentioned objectives, so that focusing on one of them may lead to inappropriate condition for another one. Higher release flows are required to meet the environmental flow demand, downstream demand and mean concentration, while lower release flows are preferred to fulfill the objectives such as reservoir reliability and suitable contact length. Nash theory can be used for resolving such conflicts. 


\subsection{Minimum permissible level}

Using the Tennant method, the minimum permissible level for the environmental flow was determined as the minimum flow for Dez River $\left(10 \mathrm{~m}^{3} \cdot \mathrm{s}^{-1}\right)$. Since, this level can cause many harms to the wild life and environment, the values greater than or equal to the maximum level can be considered for determining the minimum permissible level. However, to establish a statistical base for this value, sum of the biggest datum and the standard deviation of the data related to each objective are used as the minimum permissible level. Therefore, the value of standard deviation for the objectives calculated for each release flow was added to the maximum value of mean concentration and contact length. For reservoir reliability, the inflow rate to Dez Dam $\left(144.70 \mathrm{~m}^{3} . \mathrm{s}^{-}\right.$

$\left.{ }^{1}\right)$ could be considered as the minimum permissible flow rate. In this flow rate, no water would be stored in the dam and the whole water entered the dam would be discharged from it. In this way, none of the objectives of the dam would be fulfilled. To supply the downstream demand with respect to the volume and quality of the required water, the minimum release flow from dam can be considered as the minimum permissible level. Knowing that the lower river flow rate is the main reason for low water quality in the downstream areas, increase of river flow rate can contribute to the increase of the quality of river water and supply the required water volume for the downstream demand. Therefore, the downstream demand could be addressed by selecting the minimum release flow rate as the minimum permissible level.

\subsection{Assigning relative weights to objectives}

After defining the minimum permissible level and normalizing the data of the given objectives, relative weights should be assigned to each objective based on its importance. Knowing that these weights depend on many factors such as economic, social and climatic conditions and considering the relativity of objectives and changes in managerial trends, three scenarios were defined. In these scenarios, the relative weights could change with the qualitative and quantitative changes to allow for evaluation of different cases. After determining the relative weights of objectives, results of Nash equilibrium was obtained for each scenario.

\subsubsection{The first scenario}

In this scenario, an equal weight was considered for all the objectives. Moreover, coefficients of Nash function were calculated for both values of release flow in different flow rates and BODs obtained from simulation (Fig 6). The release flow corresponding to the highest value of Nash function was considered as the optimal state in this scenario. The calculated rate for this flow was $67 \mathrm{~m}^{3} . \mathrm{s}^{-1}$. The mean concentration along the river was calculated by obtaining BOD concentrations in different flow rates and distances using the Qual-2k model. The mean concentration was $2.175 \mathrm{mg} \cdot \mathrm{L}^{-1}$ and the contact length was $155 \mathrm{~km}$. The level mentioned for release flow can preserve the river in a good or even perfect condition. In Dez Dam, the release flow of $67.45 \mathrm{~m}^{3} . \mathrm{s}^{-1}$ is appropriate for reservoir reliability but inappropriate for supplying the downstream demand. Bejarano et al., (2019) applied different scenarios for environmental flow regimes and illustrated that flows could significantly affect the environmental and power generation costs. This implies the necessity of developing the best operational plan for water management Farhadian et al., (2020) considered the maximum diffusion calculated by Nash function $\left(183.8 \mathrm{~m}^{3} . \mathrm{s}^{-1} 1\right)$ as the optimum diffusion in this scenario.

\subsubsection{The second scenario}


In this scenario, the relative weights assigned to quantitative objectives (i.e satisfying the environmental flow demand, downstream demand and archiving a proper reliability) are 1.5 and 2 times greater than the weights of qualitative objectives (i.e. mean concentration and contact length). In this scenario, values of point function of Nash were calculated for different release flows at the environmental zone. Moreover, the optimal flows for quantitative coefficients of 1.5 and 2 were estimated as $63 \mathrm{~m}^{3} \cdot \mathrm{s}^{-1}$ and $57 \mathrm{~m}^{3} \cdot \mathrm{s}^{-1}$, respectively (Figs 7 and 8). The higher weights of quantitative objectives resulted in lower release flow rates probably due to water storage for quantitative objectives. Farhadian et al., (2020) based on the performance of Nash theory, calculated the optimal diffusion rate as $141.8 \mathrm{~m}^{3} . \mathrm{s}^{-1}$ in this scenario.

\subsubsection{The third scenario}

In this scenario, the relative weights assigned to qualitative objectives are 1.5 and 2 times greater than the weights of quantitative objectives. Values of Nash function coefficient were calculated for different release flows at the environmental zone. According to (Figs 9 and 10), the optimal flow rates of $75 \mathrm{~m}^{3} \cdot \mathrm{s}^{-1}$ and $87 \mathrm{~m}^{3} \cdot \mathrm{s}^{-1}$ were obtained for qualitative coefficients of 1.5 and 2 , respectively. In this scenario, the higher the weights of qualitative objectives, the higher is the release flow. This can be attributed to increase of the release flow rates and decrease of the pollutants concentrations.

Higher weight coefficients of qualitative objectives increase the release flow rate and decrease the contact length and mean concentration. The results obtained from different scenarios are presented in Table 7. Farhadian et al., (2020) estimated the optimal diffusion as $206.8 \mathrm{~m}^{3} \cdot \mathrm{s}^{-1}$ in this scenario, and suggested that the mentioned release flow rate comprised $46 \%$ of the mean natural flow of the river. According to the values obtained by the Tennant method, this release flow rate can completely satisfy the environmental demand.

Table 7: Summary of the results obtained in different scenarios

$\begin{array}{ll}\text { Discharge selected }\left(\mathrm{m}^{3} \cdot \mathrm{s}^{-}\right. & \begin{array}{l}\text { Contact } \\ \text { length }(\mathrm{km})\end{array} \quad \text { Average concentration }(\mathrm{mg} / \mathrm{l}) \\ \left.{ }^{1}\right)\end{array}$

Dez River

\begin{tabular}{llll}
\hline Scenario 1 & 67.45 & 155.45 & 2.175 \\
\hline $\begin{array}{l}\text { Scenario 2 factor of } \\
1.5\end{array}$ & 63.49 & 154.16 & 2.356 \\
\hline $\begin{array}{l}\text { Scenario 2 factor of 2 } \\
\text { factor 3Scenario }\end{array}$ & 57.17 & 152.78 & 2.592 \\
\hline $\begin{array}{l}\text { of 1.5 } \\
\text { factor of 2 3Scenario }\end{array}$ & 87.33 & 156.67 & 1.938 \\
\hline
\end{tabular}

\section{Conclusion}

To identify the optimal release flow of Dez Dam, an environmental zone was determined using the hydrological methods of Tennant and aquatic base-flow. Moreover, the Qual-2k model was used to simulate 6 quality 
parameters in Dez River. The results proved its good potential for simulation of the studied quality parameters including BOD. Next, the optimal river flow was determined by Game theory, and different qualitative and quantitative scenarios were studied using the Nash multiplying function. For this purpose, three scenarios were defined and different weights were assigned to the qualitative and quantitative objectives in each scenario. In the first scenario, similar weights were assigned to each objective; in the second scenario, coefficients of 1.5 and 2 were considered for weights of quantitative objectives; and in the third scenario, coefficients of 1.5 and 2 were considered for weights of qualitative objectives. According to the results, different release flows and flow rates were obtained for Dez River in each scenario. Considering three scenarios using the factors of 1.5 and 2, the flow rates of Dez River were calculated as $67,63,57,75$ and $87 \mathrm{~m}^{3} \cdot \mathrm{s}^{-1}$, respectively. As seen, with increases in qualitative and quantitative objectives of the problem, the optimal release flows are decreased and increased, respectively. The results also indicated that the flow rates were considerably changed with the changes in the weights of objectives. This was found to be an important factor in the optimization method and an effective element in the decisions made by managers based on the social and economic conditions of the affected areas.

\section{Declarations}

Ethics approval: Not Applicable.

Consent to publish: Not Applicable.

Consent to Participate: Not Applicable.

Availability of data and materials: Data sharing is not applicable to this article as no datasets were generated or analyzed during the current study.

Competing interests: The authors declare no competing interests.

Authors Contributions: All authors contributed to the study conception and design. Material preparation, data collection and analysis were performed by Amir Foroughian, Ehsan Derikvand, Hossein Eslami, and Saeb Khoshnavaz. The first draft of the manuscript was written by Ehsan Derikvand and all authors commented on previous versions of the manuscript. All authors read and approved the final manuscript.

Funding: the authors did use any funding over the course of this study.

\section{References}

Ahmad, A., El-Shafie, A., Razali, S.F.M., Mohamad, Z.S. (2014). Reservoir optimization in water resources: a review. Water Resour. Manage, 28(11), 3391-3405.

Ahmed, A.M. (2014). Prediction of dissolved oxygen in Surma River by biochemical oxygen demand and chemical oxygen demand using the artificial neural networks (ANNs). J. King Saud Univ. Eng. Sci, 29(2), 151158.

Bejarano, M.D., Sordo-Ward, A., Gabriel-Martin, I., Garrote, L. (2019). Tradeoff between economic and environmental costs and benefits of hydropower production at run-of-river-diversion schemes under different environmental flows scenarios. J. Hydrol, 572, 790-804. 
Bouaroudj, S., Menad, A., Bounamous, A., Ali-Khodja, H., Gherib, A., Weigel, D.E., Chenchouni, H. (2019). Assessment of water quality at the largest dam in Algeria (Beni Haroun Dam) and effects of irrigation on soil characteristics of agricultural lands, Chemosphere, 219, 76-88.

Cai, W., Zhang, L., Zhu, X., Zhang, A., Yin, J. (2013). Wang, H., Optimized reservoir operation to balance human and environmental requirements: A case study for the Three Gorges and Gezhouba Dams, Yangtze River basin, China. Ecol. Inf, 18, 40-48.

Chen, A., Wu, M., McClain, M.E. (2020). Classifying dams for environmental flow implementation in China. Sustainability, 12(1), 107.

Dahmani, S., Ferhait, A., Yebdri, D., Bounoua, R., Khodja, H.D. (2018). Development of Reservoir Management Optimal Rules: Case of Hammam Boughrara Dam, Wilaya of Tlemcen, Algeria. In Advances in Hydroinformatics, Springer, Singapore, 347-358.

Dehghanipour, A.H., Schoups, G., Zahabiyoun, B., Babazadeh, H. (2020) Meeting agricultural and environmental water demand in endorheic irrigated river basins: A simulation-optimization approach applied to the Urmia Lake basin in Iran. Agric. Water Manage, 241, 106353.

Farhadian, M., Bozorg Haddad, O., Loáiciga, H. A., Fulfillment of river environmental flow: Applying Nash theory for quantitative-qualitative conflict resolution in reservoir operation. Water Environ. J, 2020, 1-31.

Harsanyi, J.C., Selten, R. (1988). A general theory of equilibrium selection in games. MIT Press Books, 1.

Karimi, S., Salarijazi, M., Ghorbani, K. (2017). River environmental flow assessment using Tennant, Tessman, FDC Shifting and DRM hydrological methods. Iran. J. Echohydrol, 4(1): 177-189.

Mazvimavi, D., Madamombe, E., Makurira, H. (2007). Assessment of environmental flow requirements for river basin planning in Zimbabwe. Phys. Chem. Earth, Parts A/B/C, 32(15-18), 995-1006.

Mishra, S.K., Amrit, K., Pandey, R.P. (2019). Correlation between Tennant method and standardized precipitation index for predicting environmental flow condition using rainfall in Godavari Basin. Paddy Water Environ, 17(3), 515-521.

Nafarzadegan, A.R., Vagharfard, H., Nikoo, M.R., Nohegar, A. (2018). Socially-optimal and Nash Pareto-based alternatives for water allocation under uncertainty: an approach and application. Water Resour. Manage, 32(9), 2985-3000.

Park, S.S., Lee, Y.S. (2002). A water quality modeling study of the Nakdong River, Korea. Ecol. Modell, 152(1), 6575.

Parrachino, I., Dinar, A., Patrone, F. (2006). Cooperative game theory and its application to natural, environmental, and water resource issues: 3. application to water resources. The World Bank.

Pourghasemi, H.R., Yousefi, S., Sadhasivam, N., Eskandari, S. (2020). Assessing, mapping, and optimizing the locations of sediment control check dams construction. Sci. Total Environ, 739, 139954. 
Saghi, H., Karimi, L., Javid, A.H. (2015). Investigation on trophic state index by artificial neural networks (case study: Dez Dam of Iran). Appl. Water Sci, 5(2), 127-136.

Suwal, N., Huang, X., Kuriqi, A., Chen, Y., Pandey, K.P., Bhattarai, K.P. (2020). Optimisation of cascade reservoir operation considering environmental flows for different environmental management classes. Renewable Energy, 453-464.

Theodoropoulos, C., Georgalas, S., Mamassis, N., Stamou, A., Rutschmann, P., Skoulikidis, N. (2018). Comparing environmental flow scenarios from hydrological methods, legislation guidelines, and hydrodynamic habitat models downstream of the Marathon Dam (Attica, Greece). Ecohydrol, 11(8), e2019.

Wang, Q., Li, S., Jia, P., Qi, C., Ding, F. (2013). A review of surface water quality models. Sci. World J.

Watt, S.P., Watt, E., Anderson, B. (2007). A methodology for environmental protection of Ontario watercourses with respect to the permit to take water program, A Thesis of Civil Engineering for the degree of Master of Science (Engineering), Queen's University Kingston, Ontario, Canada.

Wei, G., Yang, Z., Cui, B., Li, B., Chen, H., Bai, J., Dong, S. (2009). Impact of dam construction on water quality and water self-purification capacity of the Lancang River, China. Water Resour. Manage, 23(9), 1763-1780.

Yustiani, Y.M., Wahyuni, S., Dewi, S.N.F. (2019). Determination of maximun BOD load using water quality modelling of upstream Citarum river. Int. J, 16(56), 118-122.

Zhang, R., Gao, H., Zhu, W., Hu, W., Ye, R. (2015). Calculation of permissible load capacity and establishment of total amount control in the Wujin River Catchment-a tributary of Taihu Lake, China. Environ. Sci. Pollut. Res, 22(15), 11493-11503.

\section{Figures}




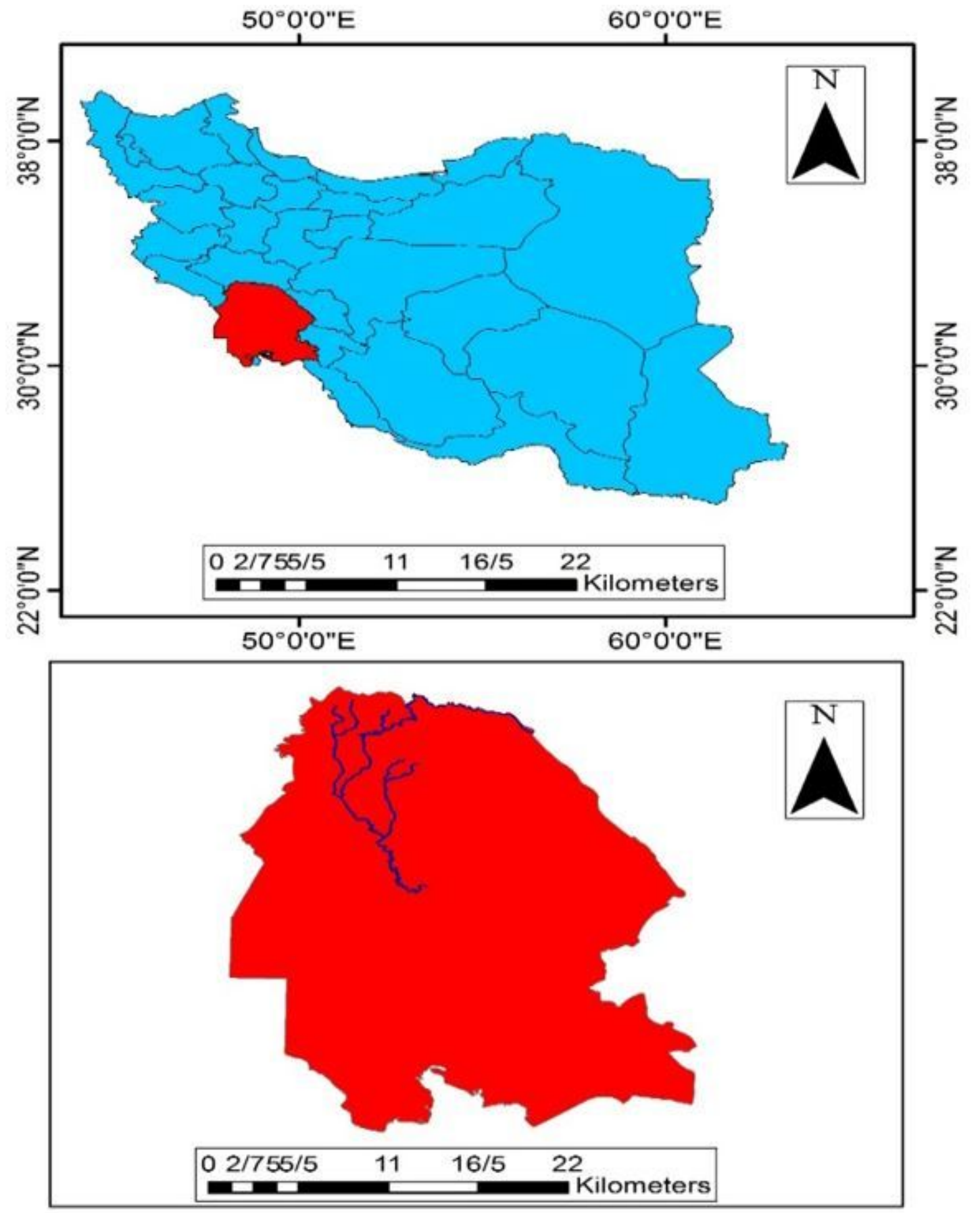

Figure 1

Location of Dez Dam in Iran 

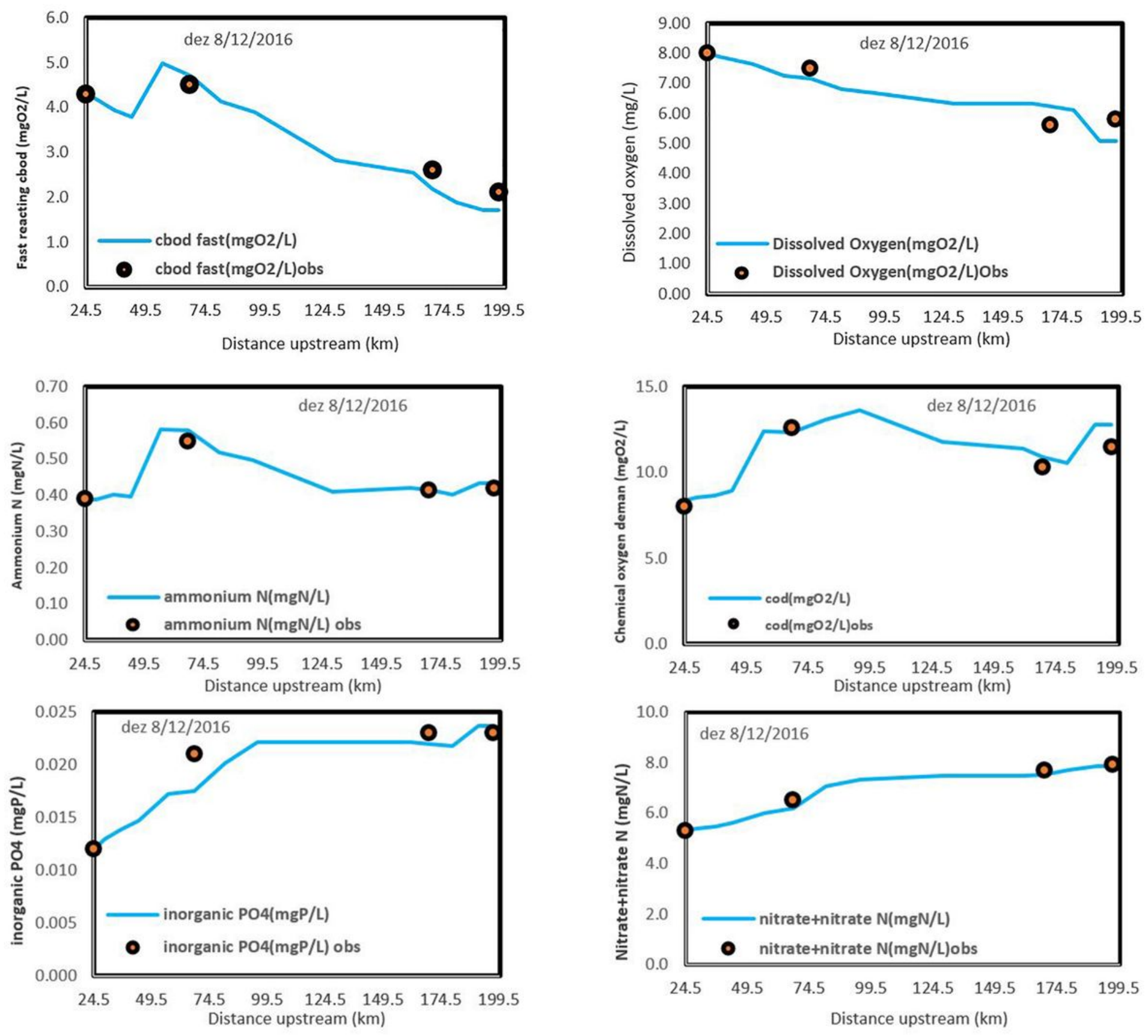

Figure 2

Changes in the measured or simulated data of the model in 2016 


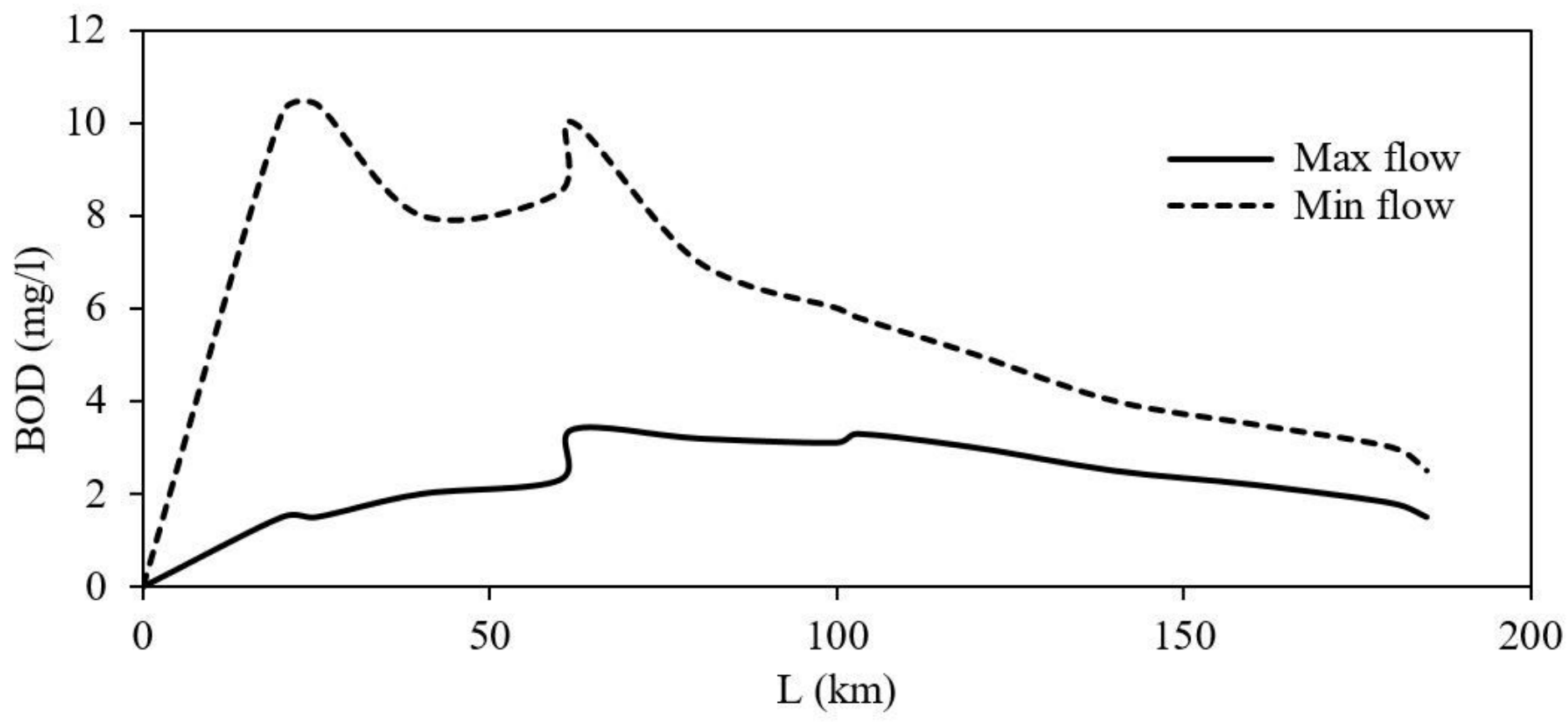

Figure 3

Simulation of the river's BOD at minimum and maximum long-term flows

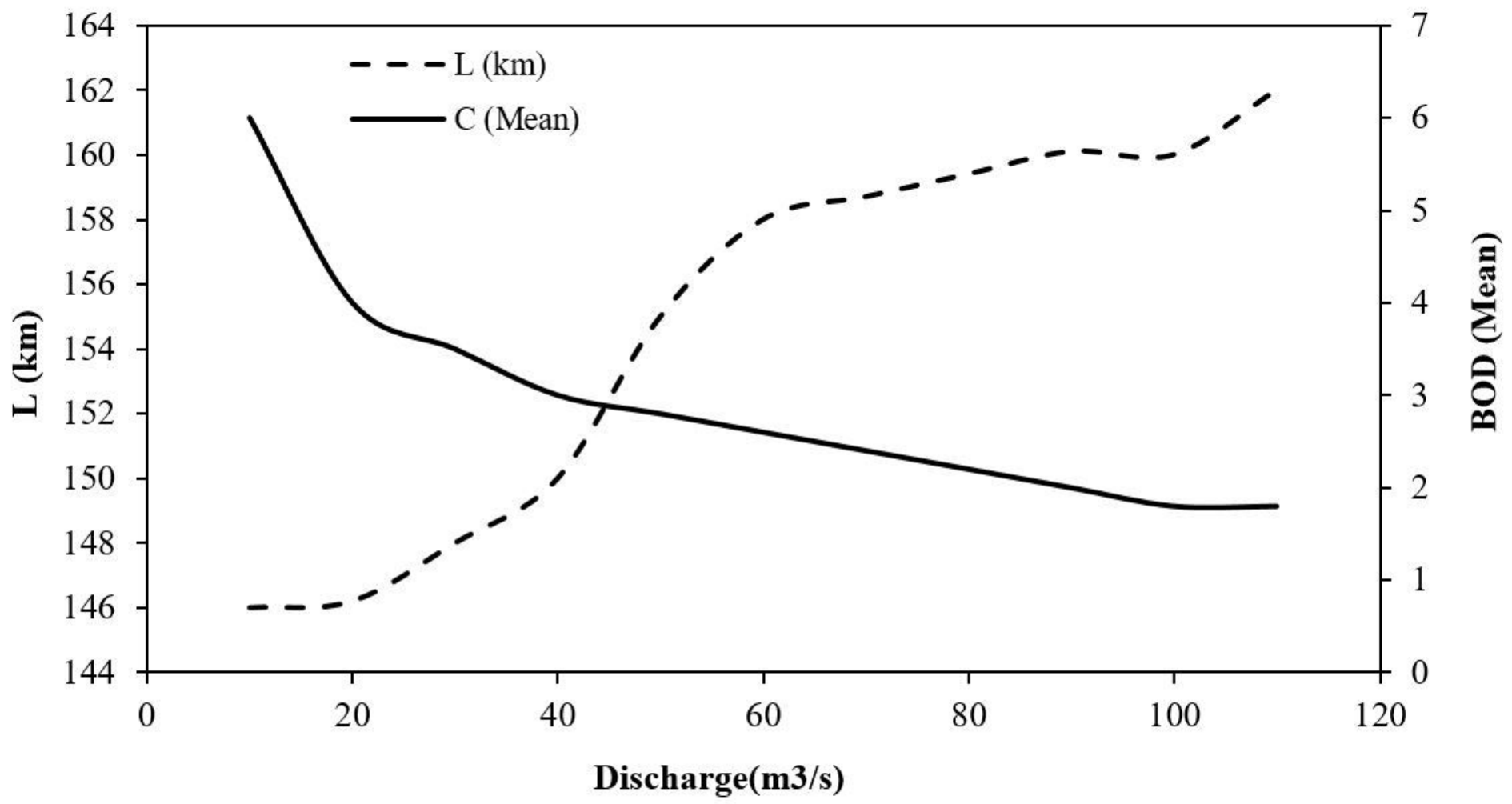

Figure 4

Mean change of concentration and contact length in different flows 


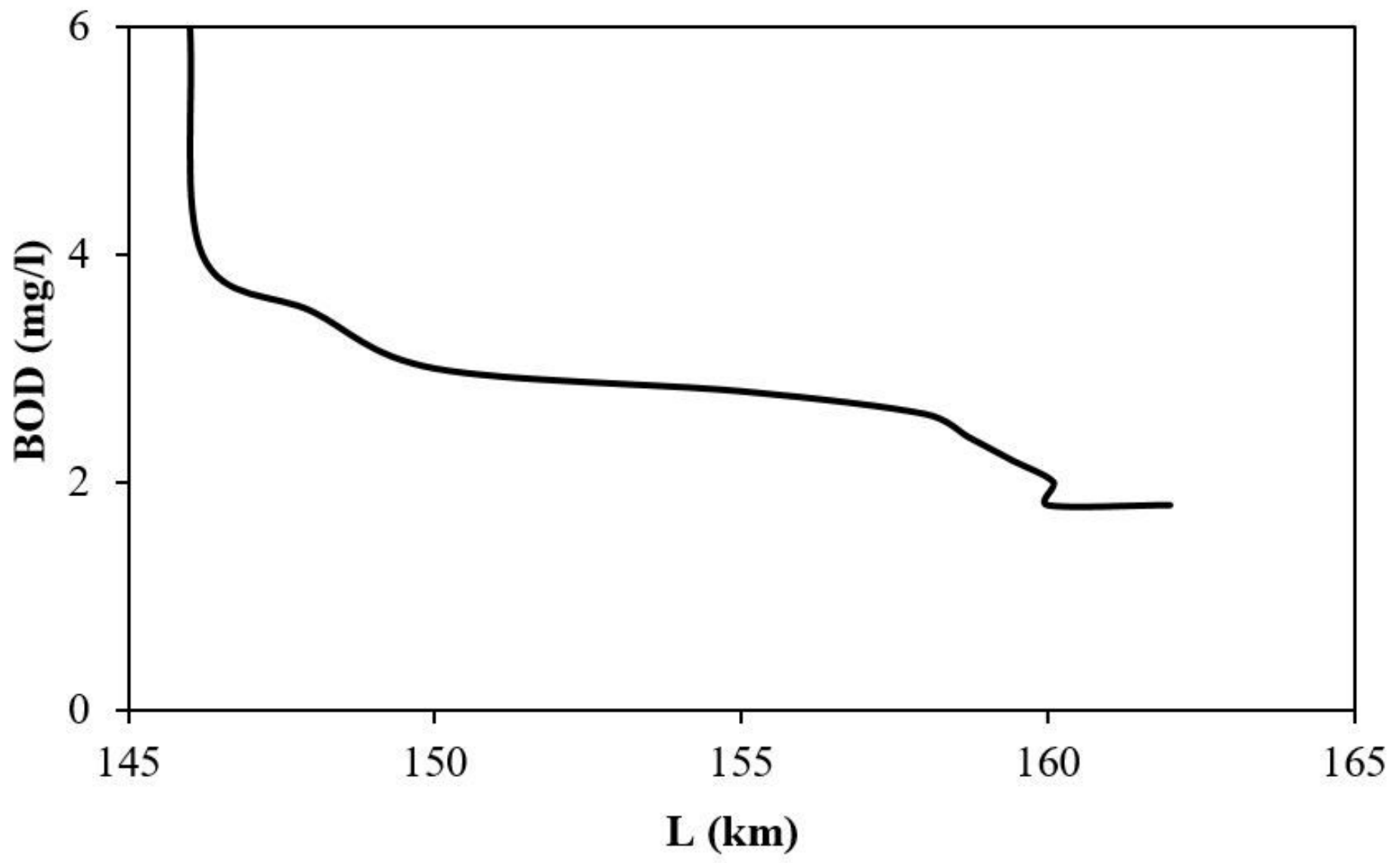

Figure 5

Mean concentration and contact length of Dez River 


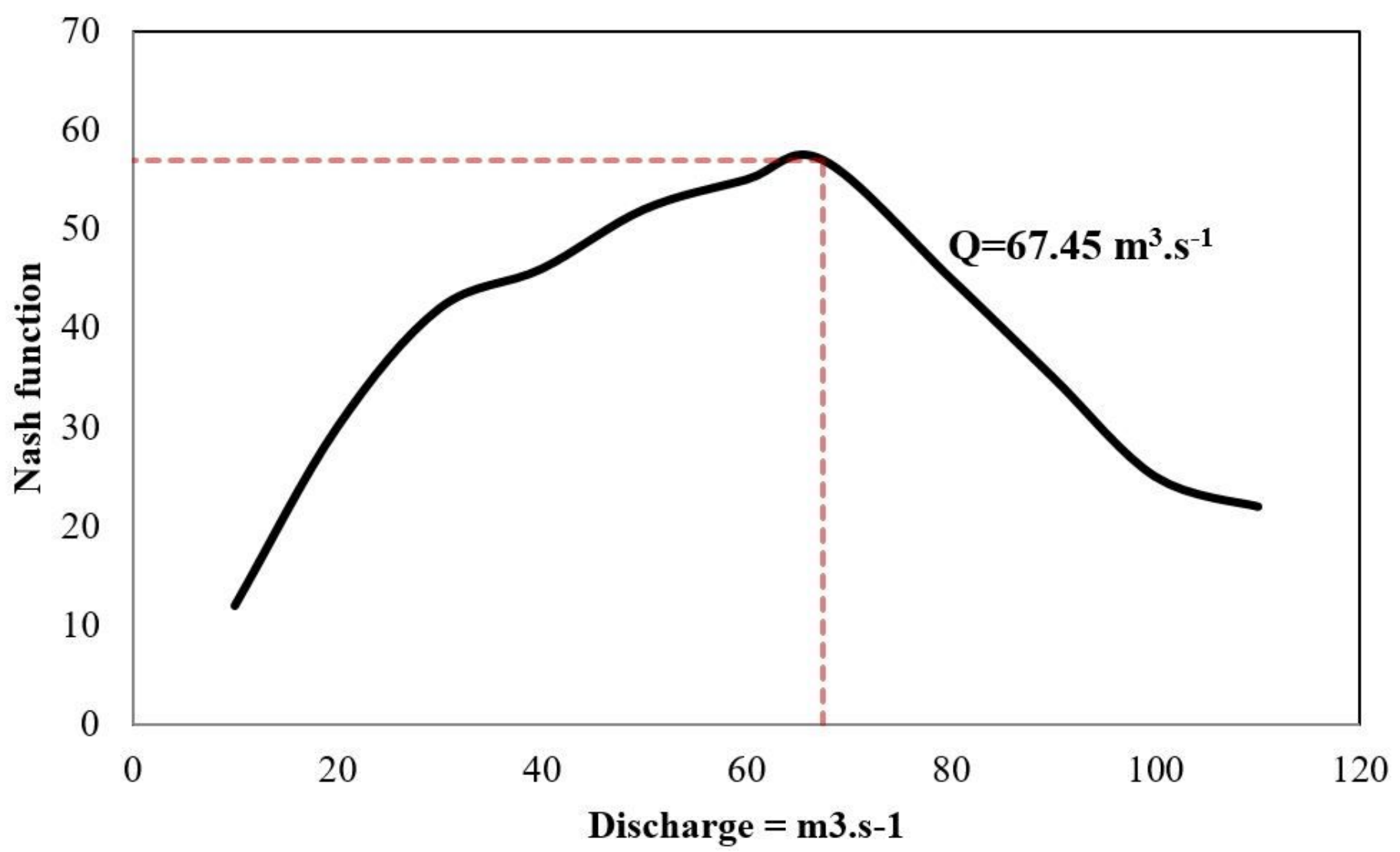

Figure 6

Changes of Nash function in the first scenario

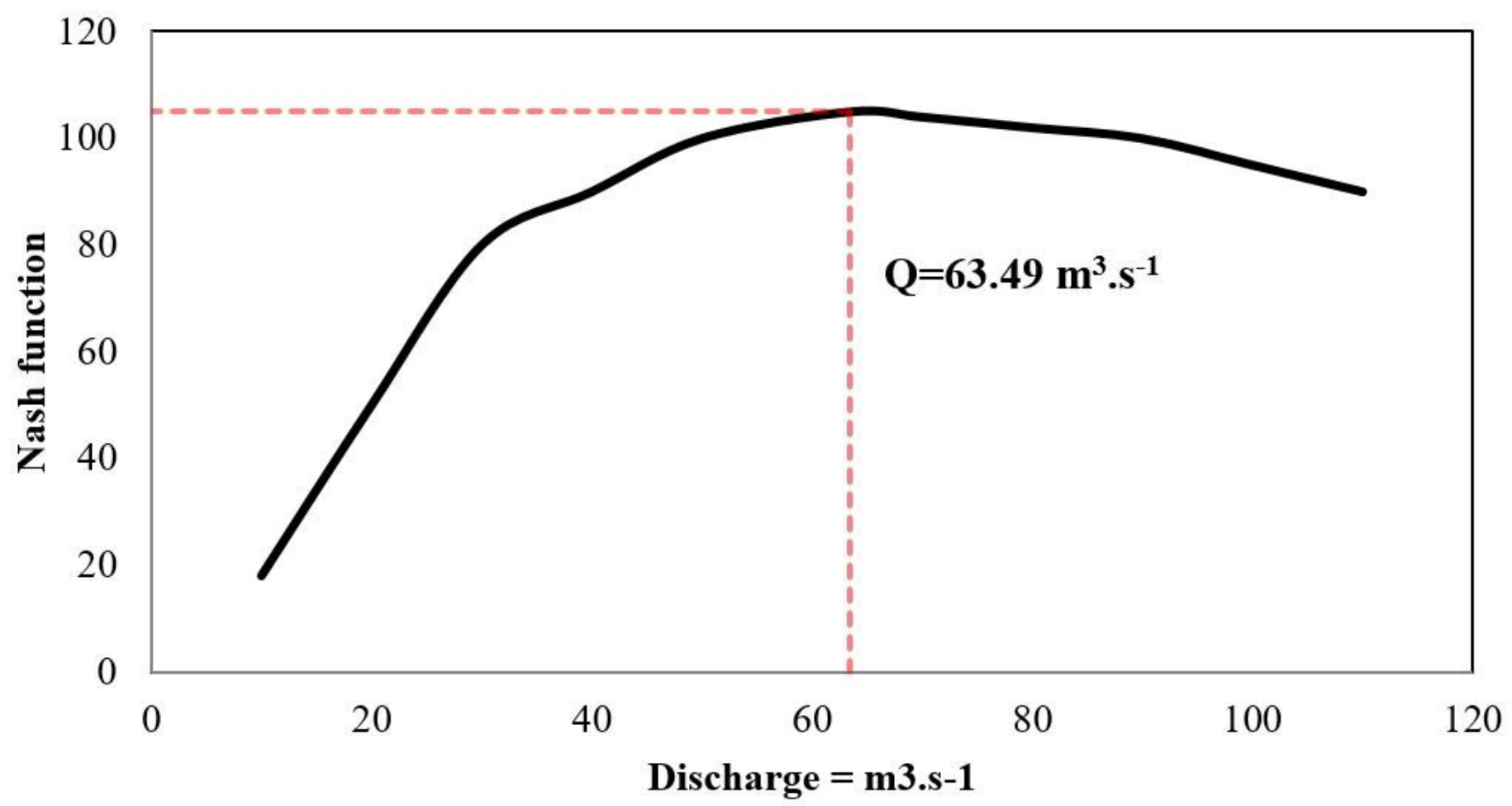

Figure 7 
changeof Nash function in the second scenario with coefficient of 1.5

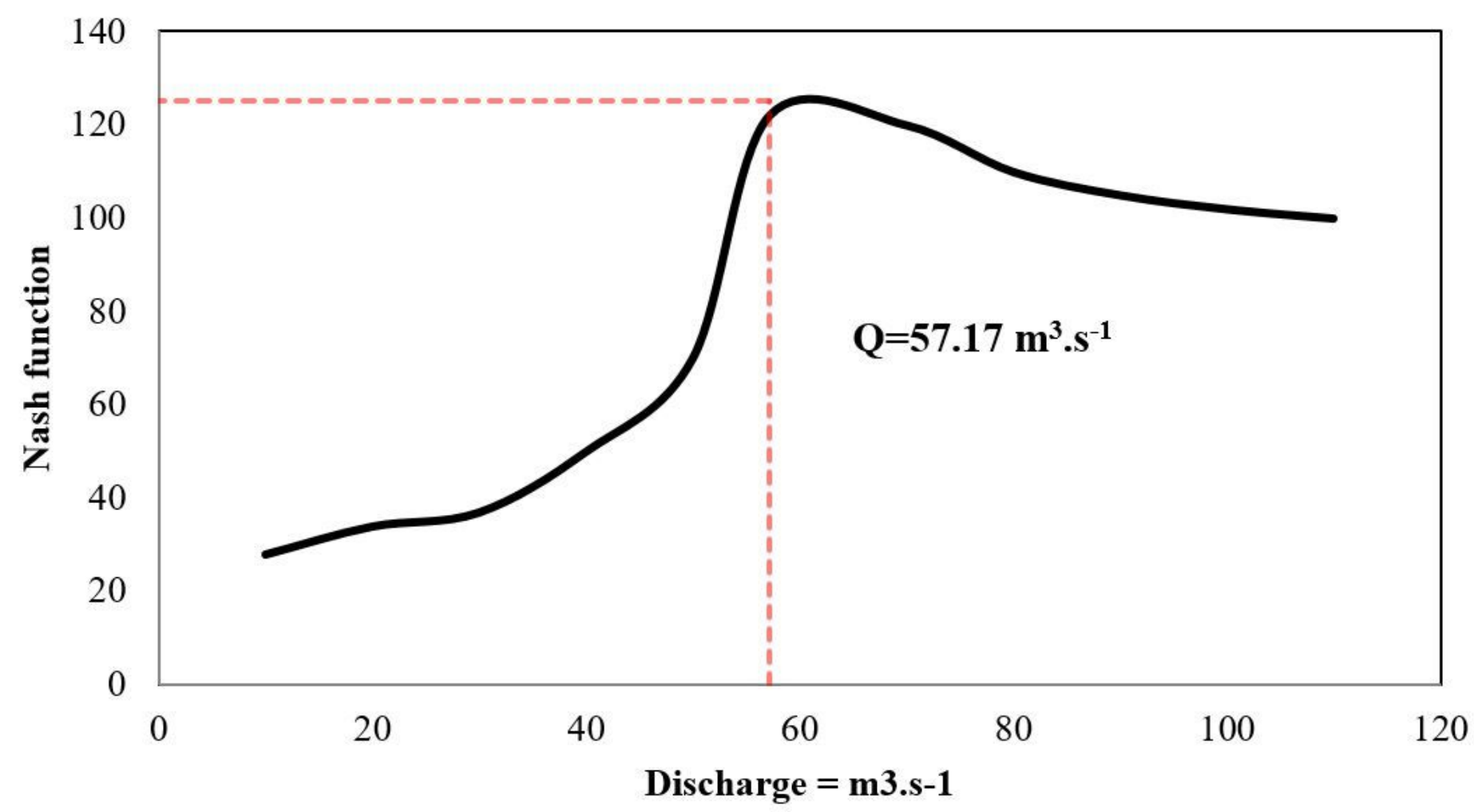

Figure 8

Changes of Nash function in the second scenario with coefficient of 2

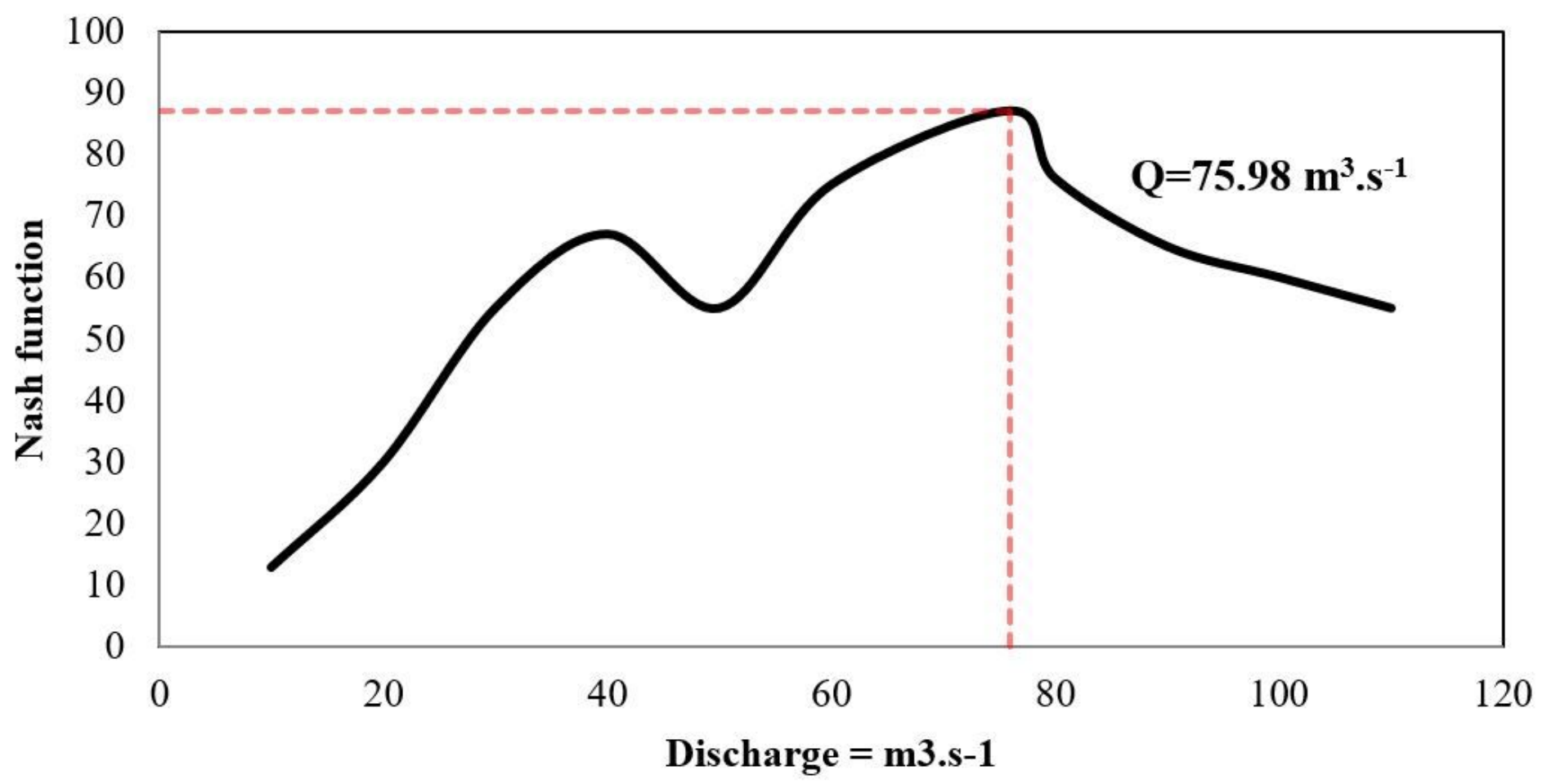

Figure 9 
Changes of Nash function in the third scenario with coefficient of 1.5

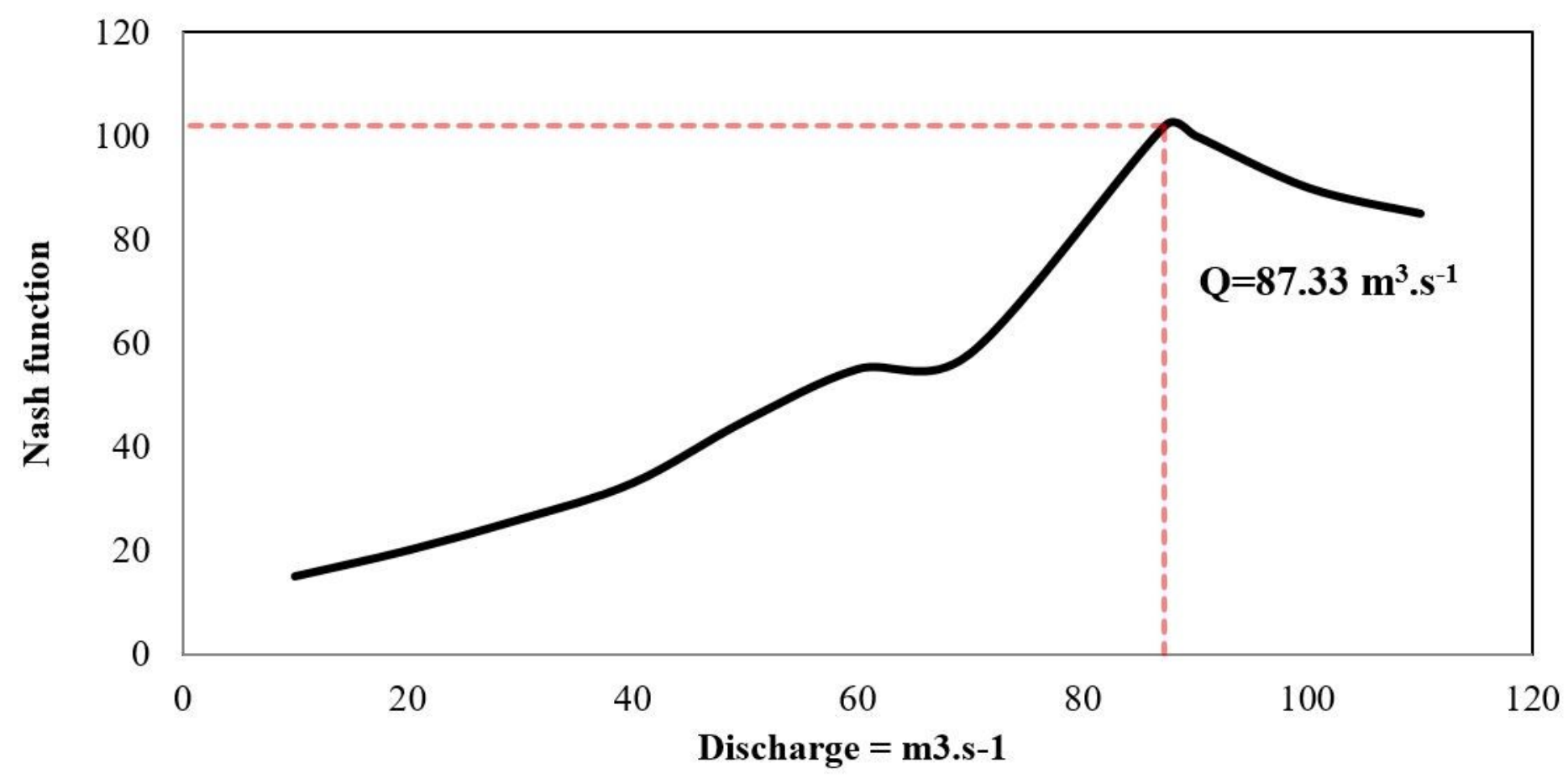

Figure 10

Changes of Nash function in the third scenario with coefficient of 2 